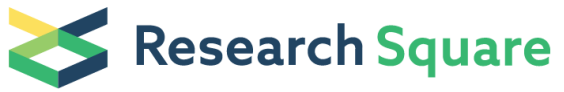 \\ Preprints are preliminary reports that have not undergone peer review. \\ They should not be considered conclusive, used to inform clinical practice, or referenced by the media as validated information.
}

\section{Chronic Effects of Different Intensities of Interval Training on Hemodynamic, Autonomic and Cardiorespiratory Variables of Physically Active Elderly People}

\section{Leandro Sant'Ana ( $\sim$ leandrosantana.edufisica@hotmail.com )}

Post Graduate Program in Physical Education, Federal University of Juiz de Fora, Minas Gerais Jeferson Vianna

Post Graduate Program in Physical Education, Federal University of Juiz de Fora, Minas Gerais

\section{Aline Ribeiro}

Post Graduate Program in Physical Education, Federal University of Juiz de Fora, Minas Gerais

\section{Natália Reis}

Post Graduate Program in Physical Education, Federal University of Juiz de Fora, Minas Gerais

João Guilherme Silva

Post Graduate Program in Physical Education, Federal University of Juiz de Fora, Minas Gerais

\section{Yuri Campos}

Post Graduate Program in Physical Education, Federal University of Juiz de Fora, Minas Gerais

\section{Estevão Monteiro}

School of Physical Education and Sports, Federal University of Rio de Janeiro, Rio de Janeiro

\section{Amanda Brown}

School of Physical Education and Sports, Federal University of Rio de Janeiro, Rio de Janeiro

\section{Jefferson Novaes}

School of Physical Education and Sports, Federal University of Rio de Janeiro, Rio de Janeiro

\section{Fabiana Scartoni}

Sport and Exercise Science Laboratory, Catholic University of Petrópolis, Rio de Janeiro

\section{Sérgio Machado}

Laboratory of Physical Activity Neuroscience, Salgado de Oliveira University, Rio de Janeiro

\section{Henning Budde}

Faculty of Human Sciences, Medical School Hamburg, University of Applied Science and Medical University, Hamburg 20457

\section{Research Article}

Keywords: Interval training, Cardioprotection, Seniors, Cardiovascular Health

Posted Date: February 2nd, 2021

DOI: https://doi.org/10.21203/rs.3.rs-149552/v1 
License: (9) (1) This work is licensed under a Creative Commons Attribution 4.0 International License. Read Full License 


\section{Abstract \\ Background}

Interval training is an important strategy for promoting physiological adaptations. Therefore, this study aimed to verify the chronic effects of interval training ( $\mathrm{TI}$ ) with different intensities on hemodynamic, autonomic and cardiorespiratory variables of physically active elderly people.

\section{Methods}

Twenty-four physically active older men (age: $68.8 \pm 6.8$ years, body mass: $74.4 \pm 18.1 \mathrm{~kg}$, height: $170 \pm 8 \mathrm{~m}$, body mass index: $\left.25.1 \pm 2.2 \mathrm{~kg} / \mathrm{m}^{2}\right)$ participated in the study. Participants were randomized into three experimental groups: training group $A\left(T G_{A}, n=8\right)$, training group $B\left(T G_{B}, n=8\right)$, and control group $(G C, n=8) . T G_{A}$ and $T G_{B}$ groups performed 32 training sessions separated by a 48-hour interval. $\mathrm{TG}_{\mathrm{A}}$ showed 4-min with intensity relative to 55 to $60 \%$ of the $\mathrm{HR}_{\max }$ and $1-\mathrm{min}$ at 70 to $75 \%$ of the $\mathrm{HR}_{\max } \cdot \mathrm{TG}_{\mathrm{B}}$ training group performed the same protocol but performed 4-min at 45 to $50 \% \mathrm{HR}_{\max }$ and 1 -min at 60 to $65 \% \mathrm{HR}_{\max }$. Both training groups performed each series for six times, totaling 30-min per session. The evaluations were carried out in the pre (baseline) moments after the 16th and 32nd intervention sessions. GC only carried out assessments. Hemodynamic variables $\left(H_{R}, S B P, D B P\right.$, $\mathrm{MBP}$, and DP), autonomic (HRV indices, in the time and frequency domain), and cardiorespiratory $\left(\mathrm{VO}_{2 \mathrm{max}}\right.$ estimated) variables were evaluated.

\section{Results}

There were no statistically significant differences in comparisons between protocols and moments $(p>0.05)$. However, the size of the effect and the percentage delta indicated clinical results with relevant magnitudes between protocols and moments, indicating favorable responses to the IT intervention in hemodynamic, autonomic, and cardiorespiratory variables.

\section{Conclusion}

IT can be an essential strategy in the prescription of training for conditional improvement of variables of cardioprotective function in physically active and healthy older people. However, other studies are suggested to establish the efficiency of this method for cardiovascular and cardiorespiratory variables in the elderly.

\section{Introduction}

According to the World Health Organization, the number of older people has increased significantly [1]. Aging is something natural and inevitable so that it will be in constant progress in the coming years across the world [2]. Because of this, the American College of Sports Medicine (ACSM) and the American Heart Association (AHA) directed several positions on the importance of physical training in improving cardiovascular and cardiorespiratory fitness specifically for the elderly population [3]. 
Physiological changes in aging can be partially reduced by regular physical exercise to improve the cardiovascular system [4-6] and cardiorespiratory fitness [7]. Aging brings several changes in the cardiovascular system [8]. Disorders related to the cardiovascular and cardiorespiratory system are known to be the leading cause of disease and mortality worldwide $[9,10]$ and appear to have more significant effects on the elderly[11]. Additionally, with the aging process, the cardiovascular functional decline is significant [12], where the maintenance and improvement of this system are essential for the organic integrity of the elderly [11].

The cardiovascular system, among other factors such as endocrine factors, is driven by autonomic [13] and hemodynamic $[14,15]$ actions, in which an integrated way provides the functional efficiency of this system [16]. The cardiorespiratory system is also essential in cardiovascular potential and efficiency, which can suffer significant functional reductions due to aging [17]. However, these systems require attention in the conditional improvement of their actions $[18,19]$. Studies report that the harmful physiological effects in the elderly are not only related to aging but also lifestyle habits, such as regular physical activity $[20,21]$ mention that aging is not a limiting factor in the autonomic nervous system. Therefore, the improvement in physical conditioning linked to cardiovascular and cardiorespiratory efficiency, especially in the face of aging $[5,22]$.

To maintain, and improve cardiovascular and cardiorespiratory functions in older men, one of the strategies is to promote an increase in the aerobic capacity, for example, maximum oxygen uptake $\left(\mathrm{VO}_{2 \mathrm{max}}\right.$ [23]. In this objective, it appears that interval training (IT) has excellent potential for cardiovascular and cardiorespiratory improvement [24]. Previous studies have reported increases in $\mathrm{VO}_{2 \max }$ to reduce the risk of death from cardiovascular and cardiorespiratory events ( $\pm 15 \%$ ) [9]. Therefore, to improve the aerobic capacity, specific training is required, and IT seems to promote chronic response [25]. Additionally, IT well suggested to improve the maximum aerobic profile in the elderly [26] and increase autonomic and hemodynamic balance [27], thus consolidating an improvement in the cardiovascular system.

Currently, IT related studies have been applied using stimulus intensities above metabolic and ventilatory thresholds, such as training with high-intensity intervals. Also, studies have used IT assessing individuals of different ages and objectives for physiological analyzes [28-30]. Therefore, currently, there is little research using IT at intensities below the physiological thresholds, for example, anaerobic and ventilatory threshold 2 [31], especially for the elderly. In IT, stimuli performed below physiological thresholds (e.g., anaerobic and ventilatory 2 ) can provide less mechanical and physiological wear in the elderly. Besides, uptime can be shorter and more motivating, which would be interesting for this audience.

In the elderly, another factor that can hinder the practice of some activity at higher intensities is the motor pattern. In IT, the time at higher intensities is shorter, which may provide greater fitness for the practice of exercise, and with that, IT can be a suitable training prescription option [32]. However, conditional improvements in this population become indispensable, since the physical fitness index [11] it is a determining factor to enable a greater preservation of functional and organic efficiencies and, thus, to minimize the deleterious effects caused by the low physical fitness added to the aging process [22]. Because of this need, the objective of this study is to verify the chronic effects of IT with different intensities on hemodynamic, autonomic, and cardiorespiratory variables of physically active older people.

\section{Methods}

\section{Participants}


The sample consisted of 24 older men (age: $68.8 \pm 6.8$ years, body mass: $74.4 \pm 18.1 \mathrm{~kg}$, height: $1.70 \pm 0.8 \mathrm{~m}$; $\mathrm{BMl}$ : $25.1 \pm 2,2$ ) physically active (Table 1 ). As for the selection of participants, the following conditions were considered: elderly men, regular practitioners of physical activity, but with relatively low energy expenditure and below the minimum activity time per week (150 minutes), 2 to 3 times a week, 1 hour per session. Since these activities are not related to aerobic training with the same characteristic to be applied in this study, everyone should have incompetent physical conditions to perform the intervention proposed by the study. On the other hand, the exclusion criteria were the use of any pharmacological medication and/or ergogenic resources (blood pressure control drugs, beta-blockers, among others related to cardiovascular and cardiorespiratory control) that could influence the expected results in some way, presenting musculoskeletal disorders that compromise training. Also, all participants received a recommendation not to eat foods that could interfere with cardiovascular and cardiorespiratory responses (excessive consumption of salt, caffeine, alcohol, high-calorie foods, among others). After explaining the risks and benefits of the research, the subjects completed the Physical Activity Readiness Questionnaire (PAR-Q). They signed an informed consent form prepared following the Declaration of Helsinki. The study complied with Resolution 466/12 of the National Health Council (CNS). The local Ethics and Research Committee approved it of the Salgado de Oliveira University, Rio de Janeiro, Brazil, registered with the protocol: CAAE: 48827415.8.0000.5289.

\section{Experimental Design}

Participants were randomized to 3 experimental groups: The training group $A\left(T_{A}, n=8\right)$, the training group $B$ $\left(T G_{B}, n=8\right)$, and the control group ( $\left.C G, n=8\right)$. For groups that trained, the interventions developed for 32 sessions, with a 48-hour interval between one and the other session. the $\mathrm{TG}_{\mathrm{B}}$ group, one of the participants, had to suspend his participation in the research (at the beginning of the interventions), for personal reasons. Thus, a selection of another individual made to compose the group, therefore, maintain the same number of individuals in the three groups $(n=8)$. In the $T G_{A}$ and $C G$, there was no dropout (Figure 1). The evaluations performed in the pre (baseline) moments after the $16^{\text {th }}$ and $32^{\text {nd }}$ intervention sessions. The control group did not carry out any intervention; they continued with their daily domestic activities, but without carrying out activities such as walking, cycling, or any other activities that could interfere with the level of physical fitness already existing in these individuals. However, they carried out the evaluations in the same period of the training group.

\section{Analyses of Cardiovascular Variables}

For hemodynamic analysis, the values of resting heart rate $\left(\mathrm{HR}_{\mathrm{R}}\right)$, systolic blood pressure (SBP), and diastolic blood pressure (DBP) were analyzed. BP values were collected in the left arm [33,34]. The variables were analyzed within 10 minutes with the subjects at rest in the sitting position. For $\mathrm{HR}_{\mathrm{R}}, \mathrm{SBP}$, and $\mathrm{DBP}$, the average of the $8^{\text {th }}$ and $9^{\text {th }}$ minute of measurement performed in 10 minutes was used. After the blood pressure (BP) data was determined, the mean arterial pressure $(\mathrm{MBP})$ was calculated using the formula MBP $=\mathrm{SBP}+(\mathrm{DBP} \times 2) / 3$. Then, using the $\mathrm{HR}_{\mathrm{R}}$, the double product (DP) using the equation: $\left[\mathrm{HR}_{\mathrm{R}}(\mathrm{bpm}) \times \mathrm{SBP}(\mathrm{mmHg})\right]$. The DP represents the workload or oxygen demand of the heart and is considered a non-invasive reference for cardiac overload [35].

For the autonomic analysis, the behavior of heart rate variability (HRV) used, measured in a 5-minute window within the rest period. Considering the mean and indices of the time domain (RR, RMSSD, and SDNN) and frequency (LF, HF, and LF / HF), both calculated by software specific to this type of treatment (Kubios HRV Standart, 3.3.1). Time-domain: normal RR (time between two adjacent heartbeats) and, after that, based on 
statistical or geometric methods (mean, standard deviation and indexes derived from the RR intervals of the histogram). The indices of fluctuations in the duration of cardiac cycles were calculated, which are the RMSSD (square root of the mean of the square of the successive differences between the adjacent normal RR intervals, in a time interval, expressed in $\mathrm{ms}$ ) and the SDNN (standard deviation of all the normal RR intervals recorded in a time interval, shown in ms). The RMSSD represents parasympathetic activity, and SDNN represents sympathetic and parasympathetic activity, but it does not allow to distinguish when the HRV changes are due to the increase in sympathetic tone or the withdrawal of vagal tone [36,37].

For the analysis of HRV in the frequency domain, low-frequency components (Low Frequency - LF) used, which corresponds to the joint action of the parasympathetic and sympathetic on the heart with the predominance of the sympathetic and the high-frequency component (High Frequency - HF) that corresponds to respiratory modulation and represents the activation of the vagus nerve [38]. Finally, we use the LF / HF ratio that we call sympatheticvagal balance. However, regarding the LF / HF ratio as an indicator of sympathetic-vagal balance, there are still controversies due to the veracity of this index as a parameter of autonomic balance $[39,40]$.

A POLAR RS800CX watch (Multisport model), Kempele, Finland ${ }^{\circledR}[41]$ used to collect $\mathrm{HR}_{\mathrm{R}}$ and HRV. For the analysis of $B P$, a digital oscillometric device of the brand OMRON M6 (HEM-7001-E) ${ }^{\circledR}$ was used [42]. For HRV treatment, the data was transferred to the computer and attached to the Polar Trainer 5 Software ${ }^{\circledR}$. Correction procedures for all data were carried out on this platform and were subsequently filed in TXT format for the start of treatment in the Kubios HRV Standart Software (using 300-second inter-beat intervals), version 3.3.1. In this, all the data collected calculated and presented in different standards so that there are broad interpretations concerning HRV.

\section{Analyses of Estimated Oxygen Uptake}

The maximum oxygen uptake $\left(\mathrm{VO}_{2 \mathrm{max}}\right)$ was estimated using the indirect method [43], which evaluated using the following protocol: 3 minutes at $5.0 \mathrm{~km} / \mathrm{h} 1$ with $1 \%$ inclination. Ahead, increments of $2 \%$ in the inclination administered every 1 -minute, aiming at the intensity of $70 \%$ of the reserve $H R\left(\mathrm{HR}_{\text {res }}\right)$. Once reached, it remained in equilibrium for $6 \mathrm{~min} . \mathrm{VO}_{2}$ was obtained at: $\mathrm{VO}_{2}=\left[0.1\right.$ (speed) +1.8 (speed) (inclination / 100) + 3.5]. $\mathrm{VO}_{2 \max }(\mathrm{ml}$.

$\left.\mathrm{kg}^{-1} \mathrm{~min}^{-1}\right)$ was calculated as: $\mathrm{VO}_{2 \max }=\left[(\mathrm{VO} 2-3.5) / \% \mathrm{HR}_{\text {res } \mathrm{P}}+3.5\right]$. The test carried out on a treadmill under the brand MOVEMENT (model RT 250) ${ }^{\circledR}$.

\section{Training Protocols}

The interval training protocol was performed in the same format for both experimental groups but with different intensities. The intensities controlled through calculations based on the maximum heart rate $\left(\mathrm{HR}_{\max }\right)$ [44], adjusted with the reserve heart rate [45]. The $\mathrm{TG}_{\mathrm{A}}$ performed 4 minutes with intensity relative to 55 to $60 \%$ of $\mathrm{HR}_{\text {res }}$ and 1 minute to 70 to $75 \%$ of $\mathrm{HR}_{\text {res }}$. The $\mathrm{TG}_{\mathrm{B}}$ training group, in turn, performed the same protocol but performed 4 minutes at 45 to $50 \%$ of $\mathrm{HR}_{\text {res }}$ and 1 minute at 60 to $65 \% \mathrm{HR}_{\text {res. }}$. In both training groups ( $A$ and $\mathrm{B}$ ), each four by one sequence considered a block, accounting for a total of 6 blocks. Equivalent thus thirty minutes in duration. At the end of each block, perception of effort was measured [46], to help with the proposed intensity control [47]. All training sessions were carried out on a treadmill using the MOVEMENT brand (model RT 250) ${ }^{\circledR}$.

\section{Statistical Analysis}


In the descriptive analysis, the means and standard deviation of the variables were calculated. Normality was not rejected by the Shapiro-Wilk test, as well as by the analysis of the histogram and Q-Q Plot and homoscedasticity confirmed by the Mauchly test', a fact that suggests a normal distribution for the collected data implying the possibility of parametric inferential treatment. The analysis of variance (ANOVA) with repeated measures was applied to test the main and interaction effects. Additionally, following the recommendations of the ACSM [48], for a more clinical determination of the acquired results, the method of effect size (ES) analysis was applied. The ES was calculated using the formula $\mathrm{d}=\mathrm{Md} / \mathrm{Sd}$, where Md is the mean difference, and Sd is the standard deviation of the differences. The ES was defined as small ( $\geq 0.2)$, medium ( $\geq 0.5)$, and large $(\geq 0.8)$ [49]. All statistical analyses were performed using SPSS software version 21 (SPSS Inc., Chicago, IL, USA), with a significance level of $5 \%(p<05)$. For the sample calculation, GPower 3.1 software was used [50].

\section{Results}

Twenty-four older people were selected (Table 1), where they randomly divided into $\mathrm{TG}_{\mathrm{A}}, \mathrm{TG}_{\mathrm{B}}$, and CG. With 8 participants for each group.

The effect size, $\mathrm{p}$-values, and $\Delta \%$ for each condition were presented in Table 2 . There were no differences between baselines values. There were no significant differences within and between protocols at any time point for resting heart rate (Fig. 2), blood pressure (Fig. 3), double product (Fig. 4), heart rate variability (Fig. 5), and $\mathrm{VO}_{2 \mathrm{max}}$ estimate ( $\mathrm{ml} . \mathrm{kg}^{-1} \mathrm{~min}^{-1}$ ) (Fig. 6). The ES indicated that all experimental protocols showed improvements in the variables blood pressure with variation between - 0.86 (Large) and - 1.11 (Large), rate pressure product with 0.52 (Moderate), heart rate variability with variation between - 0.49 (Moderate) and -4.00 (Large), $\mathrm{VO}_{2 \mathrm{max}}$ estimate $\left(\mathrm{ml} . \mathrm{kg}^{-1} \mathrm{~min}^{-1}\right)$ with variation between 0.82 (Large) and 1.12 (Large) when compared to control group.

\section{Discussion}

According to global positions [51], dysfunctions in the variables of cardioprotective function (HR and BP) are the main causes of illness and death in the world, especially in the elderly [52]. Thus, this study aimed to verify the chronic effects of IT on cardiovascular and cardiorespiratory variables of physically active older people. There were hemodynamic $\left(\mathrm{HR}_{\mathrm{R}}, \mathrm{SBP}, \mathrm{DBP}, \mathrm{MBP}\right.$, and $\left.\mathrm{DP}\right)$, autonomic $(\mathrm{HRV})$, and cardiorespiratory variables $\left(\mathrm{VO}_{2 \mathrm{max}}\right.$ estimate $\left.-\mathrm{ml} . \mathrm{kg}^{-1} \mathrm{~min}^{-1}\right)$. The intervention conducted composing 32 interval training sessions for two training groups $\left(T G_{A}\right.$ and $\left.T G_{B}\right)$. The $C G$ did not carry out the training, but the evaluations in the same period of the experimental groups (baseline, after the 16th and 32nd session).

The $\mathrm{TG}_{\mathrm{A}}$ performed the IT protocol composing six series of 4 minutes at $55-60 \% \mathrm{HR}_{\text {res }}$ with 1 minute at $70-75 \%$ $\mathrm{HR}_{\text {res }}$. And the $\mathrm{TG}_{\mathrm{B}}$ performed the same number of series, but 4 minutes at $45-50 \% \mathrm{HR}_{\text {res }}$ with 1 minute at $60-65 \%$ $\mathrm{HR}_{\text {res }}$. Therefore, the $\mathrm{TG}_{\mathrm{B}}$ carried out interventions with lower intensities. Our findings demonstrated that both training groups achieved similar results, with no significant differences between groups. $(p>0,05)$. In the same sense, intra-group results also did not show significant differences $(p>0,05)$ for all evaluated variables. However, with $\mathrm{ES}$, it was possible to demonstrate the magnitude of chronic responses in $\mathrm{HR}_{\mathrm{R}}, \mathrm{BP}, \mathrm{HRV}$, and VO $\mathrm{Vmax}_{2}\left(\mathrm{ml} \mathrm{kg}^{-1}\right.$ $\min ^{-1}$ ), resulting from the intervention with interval training with the same protocol, but with different intensities. The application of analysis with $\Delta \%$, it was also possible to perceive the magnitude of results obtained in the investigated variables when comparing evaluations after the 16th and 32nd sessions with the baseline. 
The present study had the organization of analyses and interventions similar to what Pichot et al. [20] applied. However, in this research, the authors performed the intervention with only one group, for 14 weeks, four sessions per week and the protocol was performed on a cycle ergometer containing nine series of 4 minutes at $65 \% \mathrm{HR}_{\max }$ with 1 minute at $85 \% \mathrm{HR}_{\max }$, totaling a 45-minute volume. In the present study, the interventions were carried out on a treadmill, accounting for 32 sessions distributed in 3 weekly sessions. The recovery time (4 minute) and stimulus time (1 minute), was the same as that applied by Pichot et al. [20], however, the intervention was carried out comprising six sets, totaling 30 minutes of training and in 3 groups, being two training $\left(\mathrm{TG}_{\mathrm{A}}\right.$ and $\left.\mathrm{TG}_{\mathrm{B}}\right)$ and one control (CG).

In the hemodynamic analysis, studies that intervened with IT and observed positive results. Pichot et al. [20] demonstrated positive results in $\mathrm{HR}_{\mathrm{R}}, \mathrm{SBP}, \mathrm{DBP}$, and MBP $(\mathrm{p}<0.05)$. Molmen et al. [53] applied IT to active and sedentary older people and observed improvements in $\mathrm{HR}_{R}, \mathrm{SBP}, \mathrm{DBP}(\mathrm{p}<0.05)$. Nemoto et al. [54] managed to improve the $\mathrm{HR}_{\mathrm{R}}$, SBP, and DBP of women after five weeks of intervention with IT using walking as an activity. Regarding autonomic analysis, it seems that IT is an efficient method for promoting improvements. In addition to Pichot et al. [20], other experiments also obtained positive responses in HRV $(p<0.05)$ after the intervention with IT $[27,31]$. About cardiorespiratory assessment, the IT was shown to be potential in the results, significantly improving $(p<0.05) \mathrm{VO}_{2 \max }[20,53,55]$. These findings are essential, since the elderly reduce approximately $5 \%$ and $10 \%$ of cardiorespiratory capacity, for active and sedentary individuals, respectively [43]. Considering the magnitudes of the results obtained, visualized by ES, and by the $\Delta \%$, our findings corroborate those found by the studies as mentioned earlier because we found no statistically significant difference in the crude analyses ( $p$ > 0.05).

The intensity of the stimuli still seems to be an unresolved issue. Because studies have shown positive responses with work intensities below thresholds [31] and with high-intensity stimuli above metabolic and/or ventilatory limits $[7,56]$. In the present study, the IT intervention was performed in 2 groups $\left(\mathrm{TG}_{\mathrm{A}}\right.$ and $\left.\mathrm{TG}_{\mathrm{B}}\right)$ with different stimulus intensities, being $70-75 \% \mathrm{HR}_{\max }\left(\mathrm{TG}_{\mathrm{A}}\right)$ and $60-65 \% \mathrm{HR}_{\max }\left(\mathrm{TG}_{\mathrm{B}}\right)$ and even with light to moderate, the elderly investigated improved the cardioprotective capacity, through the analysis of ES and $\Delta \%$. With that, we can deduce that there is no need to subject older people at high intensities to achieve positive results, thus avoiding these individuals from possible cardiovascular overload and osteoarticular injury.

None of the studies mentioned using the ES and $\Delta \%$ analysis methods. Our findings with these applications were positive, showing significant ES for hemodynamic, autonomic, and cardiorespiratory variables. Through the $\Delta \%$, it was also possible to demonstrate in percentage values, relevant differences in the variables evaluated after the 16th and 32nd sessions, for both training groups. These methods are valid and clinically reinforce how important IT can be for cardiovascular training for the elderly. The possible mechanisms for the responses obtained in the elderly are still uncertain, but plausible. Some cardiovascular adaptations can be affected in the elderly, such as central and peripheral functions. The aerobic stimulus can reduce the plasma level of renin, reflecting in the decrease of the renin-angiotensin system, improving the baroreflex activity, consequently the behavior of BP, HR, and HRV $[20,31]$. The improvement in capillary density, endothelial function and oxygen delivery to tissues, are factors that can influence hemodynamic and autonomic development $[19,54,56]$. Concerning $\mathrm{VO}_{2 m a x}$, successive stimuli combined with periods of recovery, make the elderly manage to impose higher intensities, and this promotes better transport capacity and consumption of $\mathrm{O}_{2}$. In addition to improving plasma hemoglobin and myoglobin volumes in muscles and increasing muscle capacity [55]. 
The present study is composed of some limitations, which may have influenced the results obtained. The number of participants could have been higher, but due to the difficulty of finding healthy older people available for research, it hindered the purpose. We were unable to reach the number of individuals for each group, determined by the sample calculation (12 individuals). We could have performed two groups (1 training and one control), as we would have the appropriate sample according to the calculation. But we aimed to generate comparisons between different training groups (different intensities), plus control, to demonstrate the potential of each level of intensity and thus enable possible information for prescriptions with this population. The sample of this study was classified as overweight by the body mass index. This may have influenced the results, in the sense that body composition directly affects cardiovascular and cardiorespiratory behavior.

Regarding the applied analysis, studies used equipment with a high level of reliability, such as for hemodynamic and autonomic evaluations performed with electrocardiogram and gas analyzer for the verification of $\mathrm{VO}_{2 \mathrm{max}}$ in maximum tests $[20,53,55]$. Our study was carried out with equipment with better accessibility, but above all, with high and validated power reliability. We chose to check $\mathrm{VO}_{2 \mathrm{max}}$ in an estimated way. However, studies that also used the estimated cardiorespiratory analysis method achieved positive results [7], which allows us to accept that the estimated method, even with limitations, can be a proper way of evaluating this functionality. Another issue that may have influenced the results with low expressiveness $(p>0.05)$ is the intensity of stimulus applied, both for $\mathrm{TG}_{\mathrm{A}}\left(70-75 \% \mathrm{HR}_{\max }\right)$ and for $\mathrm{TG}_{\mathrm{B}}\left(60-65 \% \mathrm{HR}_{\max }\right)$. Finally, another bias that limited us in the results was the stimulus time (1 minute), which possibly, together with the intensity, was not enough to promote chronic adaptations relevant to the greater hemodynamic, autonomic, and cardiorespiratory responses.

\section{Conclusion}

With the results of the present experiment, it is possible to accept that the variables evaluated here are interdependent, since the effects caused by IT, in both training groups, were similar. This reinforces the hypothesis of the high integration of the hemodynamic, autonomic, and cardiorespiratory systems. In elderly individuals, responses resulting from different exercises are more discreet, as there is a possible resistance of the entire system because of the decrease in physiological efficiency due to the aging process. However, IT can be an essential strategy in training prescription for conditional improvement of cardioprotective function variables in physically active and healthy older people. However, other studies are suggested to establish the efficiency of this method for cardiovascular and cardiorespiratory variables in the elderly.

\section{Declarations}

\section{Ethics approval and consent to participate}

The local Ethics and Research Committee approved it of the Salgado de Oliveira University, Rio de Janeiro, Brazil, registered with the protocol: CAAE: 48827415.8.0000.5289.

\section{Consent for publication}

All authors of the present study consented to the publication of the study.

\section{Availability of data and materials}


The data sets used and / or analyzed during the present study are available from the corresponding author upon request.

\section{Competing interests}

The authors declare that they have no conflicting interests

\section{Funding}

Not applicable

\section{Authors contributions}

LOS, SM, JSN, and JMV conceptualized the project. ASR, NRR, JGVS, and YAC performed the literature review. LOS, FRS, AFB, and ERM wrote the first draft of the manuscript. SM, JSN, JMV, and HB critically reviewed the manuscript regarding their areas of expertise.

\section{Acknowledgements}

Post Graduate Program in Physical Education, Federal University of Juiz de Fora (UFJF). For the scholarship to the researcher and Ph.D. student in Physical Education Leandro de Oliveira Sant'Ana. Sergio Machado was supported by a grant from Carlos Chagas Foundation for the Research Support in the State of Rio de Janeiro (FAPERJ), Young Scientists from the State of Rio de Janeiro, E -26/203.295/2017. Alexander von Gradowski accomplished the native speaker proofreading.

\section{Author Information}

\section{Affiliations}

\section{Leandro de Oliveira Sant’Ana}

Post Graduate Program in Physical Education, Federal University of Juiz de Fora, Minas Gerais, Brazil.

Strength Training Studies and Research Laboratory, Federal University of Juiz de Fora, MG, Brazil

Sport and Exercise Science Laboratory, Catholic University of Petropolis, Rio de Janeiro, Brazil

Jeferson Macedo Vianna

Post Graduate Program in Physical Education, Federal University of Juiz de Fora, Minas Gerais, Brazil

Strength Training Studies and Research Laboratory, Federal University of Juiz de Fora, MG, Brazil

\section{Aparecida de Souza Ribeiro}

Post Graduate Program in Physical Education, Federal University of Juiz de Fora, Minas Gerais, Brazil

Strength Training Studies and Research Laboratory, Federal University of Juiz de Fora, MG, Brazil 
Post Graduate Program in Physical Education, Federal University of Juiz de Fora, Minas Gerais, Brazil

Strength Training Studies and Research Laboratory, Federal University of Juiz de Fora, MG, Brazil

João Guilherme Vieira da Silva

Post Graduate Program in Physical Education, Federal University of Juiz de Fora, Minas Gerais, Brazil

Strength Training Studies and Research Laboratory, Federal University of Juiz de Fora, MG, Brazil

\section{Yuri de Almeida Costa Campos}

Post Graduate Program in Physical Education, Federal University of Juiz de Fora, Minas Gerais, Brazil

Strength Training Studies and Research Laboratory, Federal University of Juiz de Fora, MG, Brazil

Estêvão Rios Monteiro

School of Physical Education and Sports, Federal University of Rio de Janeiro, Rio de Janeiro, Brazil

\section{Amanda Brown}

School of Physical Education and Sports, Federal University of Rio de Janeiro, Rio de Janeiro, Brazil

Jefferson da Silva Novaes

School of Physical Education and Sports, Federal University of Rio de Janeiro, Rio de Janeiro, Brazil

\section{Fabiana Rodrigues Scartoni}

Sport and Exercise Science Laboratory, Catholic University of Petropolis, Rio de Janeiro, Brazil

\section{Sérgio Machado}

Laboratory of Physical Activity Neuroscience, Salgado de Oliveira University, Rio de Janeiro, Brazil

Laboratory of Physical Activity Neuroscience, Neurodiversity Institute, Queimados, RJ, Brazil

\section{Henning Budde}

Faculty of Human Sciences, Medical School Hamburg, University of Applied Science and Medical University, Hamburg 20457, Germany

\section{References}

1. Organization World Health. World Health Statistics 2016: monitoring health for sustainable development goals. World Heal Organ. 2016.

2. Chang E, Kannoth S, Levy S, Wang S, Lee JE, Becca RL. Global reach of ageism on older persons ' health: A systematic review. PLoS One. 2020;15: 1-24. 
3. Nelson ME, Rejeski WJ, Blair SN, Duncan PW, Judge JO, King AC, et al. Physical Activity and Public Health in Older Adults: Recommendation From the American College of Sports Medicine and the American Heart Association. Circulation. 2007;116: 1094-1105. doi:10.1161/CIRCULATIONAHA.107.185650

4. Lavie CJ, Arena R, Swift DL, Johannsen NM, Sui X, Lee D, et al. Exercise and the Cardiovascular System: Clinical Science and Cardiovascular Outcomes. Circ Res. 2015;117: 207-219. doi:10.1161/CIRCRESAHA.117.305205.Exercise

5. Lavie CJ, Ozemek C, Carbone S, Katzmarzyk PT, Blair SN. Sedentary Behavior, Exercise, and Cardiovascular Health. Circulation. 2019; 799-815. doi:10.1161/CIRCRESAHA.118.312669

6. Mccraty R, Shaffer F. Heart Rate Variability: New Perspectives on Physiological Mechanisms, Assessment of Self-regulatory Capacity, and Health Risk. Glob Adv Heal Med. 2015;4: 46-61. doi:10.7453/gahmj.2014.073

7. Ballesta-García I, Martínez-González-Moro I, Ramos-Campo DJ, Carrasco-Poyatos M. High-intensity interval circuit training versus moderate-intensity continuous training on cardiorespiratory fitness in middle-aged and older women: A randomized controlled trial. Int J Environ Res Public Health. 2020;17. doi:10.3390/ijerph17051805

8. Ogliari G, Mahinrad S, Stott DJ, Jukema W, Mooijaart SP, Macfarlane PW, et al. Resting heart rate, heart rate variability and functional decline in old age. CMAJ. 2015;187.

9. Kodama S, Saito K, Tanaka S, Maki M, Yachi Y, Asumi M, et al. Cardiorespiratory fitness as a quantitative predictor of all-cause mortality and cardiovascular events in healthy men and women: a meta-analysis. Jama. 2009;301: 2024-2035. doi:10.1001/jama.2009.681

10. Schroeder EC, Franke WD, Rick LS, Lee D. Comparative effectiveness of aerobic, resistance, and combined training on cardiovascular disease risk factors : A randomized controlled trial. PLoS One. 2019;14: 1-14. doi:10.1371/journal.pone.0210292 January

11. Scartoni FR, Rabelo MFP, Silva SNR, Sant'Ana LO, Scudese E, Ramos AM, et al. Physical Conditioning Index on Active Elderly Population. Biomed J Sci Tech Res. 2018;11: 8-11. doi:10.26717/bjstr.2018.11.002177

12. Sant'Ana LO, Scartoni FR, Portilho LF, Scudese E, Oliveira CQ, Senna GW. Comparison of cardiovascular variables in active elderly in different physical modalities. Brazilian J Exerc Physiol. 2019;18: 186-194. doi:10.33233/rbfe.v18i4.3232

13. Geus EJC, Gianaros PJ, Brindle RC, Jennings JR, Berntson GG. Should heart rate variability be " corrected " for heart rate ? Biological, quantitative, and interpretive considerations. Psychophysiology. 2019; 1-26. doi:10.1111/psyp.13287

14. Tamburus NY, Verlengia R, Kunz VC, César MC, Silva E. Apolipoprotein B and angiotensin-converting enzyme polymorphisms and aerobic interval training: a randomized controlled trial in coronary artery disease patients. Brazilian J Med Biol Res. 2019;51: e6944. doi:10.1590/1414-431X20186944

15. Izadi MR, Afousi AG, Fard MA, Bigi MAB. High-intensity interval training lowers blood pressure and improves apelin and NOx plasma levels in older treated hypertensive individuals. J Physiol Biochem. 2017. doi:10.1007/s13105-017-0602-0

16. Benda NMM, Seeger JPH, Stevens GGCF, Hijmans-Kersten BTP, Van Dijk APJ, Bellersen L. Effects of highintensity interval training versus continuous training on physical fitness, cardiovascular function, and quality of life in heart failure patients. PLoS One. 2015;10: e0141256. doi:10.1371/journal.pone.0141256

17. Chaves PH, Varadhan R, Lipsitz LA, Stein PK, Windhan BG, Jing T, et al. Physiological complexity underlying heart rate dynamics and frailty status in community-dwelling older women. J Am Geriatr Soc. 2008;56: 1698- 
1703. doi:10.1111/j.1532-5415.2008. 01858.x.

18. Madssen E, Arbo I, Granoein I, Walderhaug L, Moholdt T. Peak oxygen uptake after cardiac rehabilitation: A randomized controlled trial of a 12- month maintenance program versus usual care. PLoS One. 2014;9: e107924. doi:10.1371/journal.pone.0107924

19. Boidin M, Gayda M, Henri C, Hayami D, Trachsel LD, Besnier F, et al. Effects of interval training on risk markers for arrhythmic death: a randomized controlled trial. Clin Rehabil. 2019;00: 1-11. doi:10.1177/0269215519840388

20. Pichot V, Roche F, Denis C, Garet M, Duverney D, Costes F, et al. Interval training in elderly men increases both heart rate variability and baroreflex activity. Clin Aut Res. 2005;15: 107-115. doi:10.1007/s10286-005-0251-1

21. Inouye M, Abraham G, Nelson CP, Wood AM, Sweeting MJ, Dubbridge F, et al. Genomic Risk Prediction of Coronary Artery Disease in 480,000 Adults: Implications for Primary Prevention. J Am Coll Cardiol. $2018 ; 72$. doi:10.1016/j.jacc.2018.07.079

22. Fletcher GF, Landolfo C, Niebauer J, Ozemek C, Arena R, Lavie CJ. Promoting Physical Activity and Exercise. J Am Coll Cardiol. 2018;72: 1622-1639. doi:10.1016/j.jacc.2018.08.2141

23. Castro A, Duft RG, Ferreira MLV, Andrade ALLD, Gaspari AF, Silva LDM, et al. Association of skeletal muscle and serum metabolites with maximum power output gains in response to continuous endurance or highintensity interval training programs: The TIMES study - A randomized controlled trial. PLoS One. 2019;14: e0212115. doi:10.1371/journal.pone.0212115

24. Bottons L, Leighton D, Carpenter R, Anderson S, Langmead L, Ramage J, et al. Affective and enjoyment responses to 12 weeks of high-intensity interval training and moderate continuous training in adults with Crohn's disease. PLoS One. 2019;14: e0222060. doi:10.1371/journal.pone.0222060

25. Frazão DT, de Farias Junior LF, Dantas TCB, Krinski K, Elsangedy HM, Prestes J, et al. Feeling of Pleasure to High-Intensity Interval Exercise Is Dependent of the Number of Work Bouts and Physical Activity Status. PLoS One. 2016;11: 1-16. doi:10.1371/journal.pone.0152752

26. Santos A, Lonsdale C, Lubans D, Vasconcellos D, Kapsal N, Vis-Dunbar M, et al. Rates of compliance and adherence to high-intensity interval training in insufficiently active adults: a systematic review and metaanalysis protocol. BMC. 2020;9: 1-6. doi:10.1186/s13643-020-01301-0

27. Vanzella LM, Dagostinho DBB, Figueiredo MPF, Castrillón CIM, Junior JN, Vanderlei LCM. Periodized Aerobic Interval Training Modifies Geometric Indices of Heart Rate Variability in Metabolic Syndrome. Medicina (B Aires). 2019;55: 1-11.

28. Bruseghini P, Tam E, Calabria E, Milanese C, Capelli C, Galvani C. High Intensity Interval Training Does Not Have Compensatory E ff ects on Physical Activity Levels in Older Adults. Int J Envir Res Public Heal. 2020;17. doi:10.3390/ijerph17031083

29. Fisher G, Brown AW, Brown MMB, Alcorn A, Noles C, Winwood L, et al. High-intensity interval vs. moderateintensity training for improving cardiometabolic health in overweight or obese males: A randomized controlled trial. Perfusion. 2015;10: e0138853. doi:10.1371/journal.pone.0138853

30. Shepherd SO, Wilson OJ, Taylor AS, Thogersn-Ntoumani C, Adlan AM, Wagenmakers AJM, et al. Low-Volume High-intensity interval training in a gym setting improves cardio-metabolic and psychological health. PLoS One. 2015;10: e0139056. doi:10.1371/journal.pone.0139056

31. Vanzella LM, Linares SN, Miranda RAT, Silva AKF, Christófaro DGD, Netto Junior J, et al. Effects of a new approach of aerobic interval training on cardiac autonomic modulation and cardiovascular parameters of

Page 13/21 
metabolic syndrome subjects. Arch Endocrinol Metab. 2019;63. doi:10.20945/2359-3997000000111

32. Sant' Ana LO, Machado S, Ribeiro AAS, Reis NR, Campos YAC, Silva JGV, et al. Effects of Cardiovascular Interval Training in Healthy Elderly Subjects: A Systematic Review. Front Physiol. 2020;11: 1-10. doi:10.3389/fphys.2020.00739

33. ACC/AHA. Guidelines for the Management of Patients with Valvular Heart Disease. A Report of the American College of Cardiology/American Heart Association Task Force on Practice Guidelines (Writing Committee to Revise the 1998 Guidelines for the Management of Patie. Circulation. 2006;114: 450-527.

34. Kurtz TW, Griffin KA, Bidani AK, Davisson RL, Hall JE. Recommendations for blood pressure measurements in animals: summary of an AHA scientific statement from the Council on High Blood Pressure Research, Professional and Public Education Subcommittee. Arter Thromb Vasc Biol. 2015;25: 478-479.

35. Ansari M, Javadi H, Pourbehi M, Mogharrabi M, Rayzan M, Semnani S, et al. The association of rate pressure product (RPP) and myocardial perfusion imaging (MPI) findings: a preliminary study. Perfusion. 2012;27: 207-213.

36. Task Force of the European Society of Cardiology. Heart rate variability. standards of measurement, physiological interpretation, and clinical use. Circulation. 1996;93: 1043-1065.

37. Vanderlei LCM, Pastre CM, Hoshi A, Carvalho TD, Godoy MF. Noções básicas de variabilidade da frequência cardíaca e sua aplicabilidade clínica. 2009;24: 205-217.

38. Laborde S, Mosley E, Thayer JF. Heart Rate Variability and Cardiac Vagal Tone in Psychophysiological Research - Recommendations for Experiment Planning, Data Analysis, and Data Reporting. 2017;8: 1-18. doi:10.3389/fpsyg.2017.00213

39. Billman GE. The LF / HF ratio does not accurately measure cardiac sympatho-vagal balance. Front Physiol. 2013;4: 1-5. doi:10.3389/fphys.2013.00026

40. Reyes del Paso GA, Langewitz W, Mulder LJ, Roon A, Duschek S. The utility of low frequency heart rate variability as an index of sympathetic cardiac tone: a review with emphasis on a reanalysis of previous studies. Psychophysiology. 2013;50: 477-487. doi:10.1111/psyp.12027

41. Quintana DS, Heathers JA, Kemp AH. On the validity of using the Polar RS800 heart rate monitor for heart rate variability research. Eur J Appl Physiol. 2012;112: 4179-4180.

42. Topouchian JA, El Assaad MA, Orobinskaia LV, El Feghali RN, Asmar RG. Validation of two automatic devices for self-measurement of blood pressure according to the International Protocol of the European Society of Hypertension: the Omron M6 (HEM-7001-E) and the Omron R7 ( HEM 637-IT ). Blood Press Monit. 2006;6: 165-171.

43. Oliveira NA, Silveira HS, Carvalho A, Hellmuth CGS, Santos TM, Martins JV, et al. Assessment of cardiorespiratory fitness using submaximal protocol in older adults with mood disorder and Parkinson's disease. Rev Psiq Clín. 2012;40: 88-92.

44. Tanaka H, Monahan KD, Seals DR. Age-predicted maximal heart rate revisited. J Am Coll Cardiol. 2001;37: 153-156. doi:10.1016/s0735-1097(00)01054-8

45. Karvonen M, Kentala E, Mustala O. The effects of training on heart rate. A longitudinal study. Ann Med Exp Biol Fennal. 1957;35: 307-315.

46. Borg GAV. Psychophysical bases of perceived exertion. Med Sci Sport Exerc. 1982;14: 377-381.

47. Nakamura FY, Moreira A, Aoki MS. Monitoramento da carga de treinamento: A percepção subjetiva do esforço da sessão é um método confiável? Rev da Educ Física/UEM. 2010;21: 1-11. 
doi:10.4025/reveducfis.v21i1.6713

48. Pescatello LS, Franklin BA, Fagard R, Farquhar WB, Kelley GA, Ray CR. Exercise and Hypertension. Med Sci Sport Exerc. 2004; 533-553. doi:10.1249/01.MSS.0000115224.88514.3A

49. Cohen J. Statistical Power Analysis for the Behavioral Sciences. New York, NY Routledge Acad. 1988.

50. Beck TW. The importance of a priori sample size estimation in strength and conditioning research. J Strength Cond Res. 2013;27: 2323-2337.

51. ACSM. Benefits and Risks Associated with Physical Activity 1. Guidel Exerc Testing www.acsm.org. 2013; 121.

52. Williams B, Mancia G, Spiering W, Rosei EA, Azizi M, Burnier M, et al. 2018 ESC / ESH Guidelines for the management of arterial hypertension. Eur Hear J. 2018;00: 1-98. doi:10.1093/eurheartj/ehy339

53. Molmen HE, Wisloff U, Aamot IL, Stoylen A, Ingul CB. informa Aerobic interval training compensates age related decline in cardiac function. Scand Cardiovasc Journal,. 2012;46: 163-171.

doi:10.3109/14017431.2012.660192

54. Nemoto K, Gen-n H, Masuki S, Okazaki K, Nose H. Effects of High-Intensity Interval Walking Training on Physical Fitness and Blood Pressure in Middle-Aged and Older People. Mayo Clin Proc. 2007;82: 803-811. doi:10.4065/82.7.803

55. Lepretre PM, Vogel T, Brechat P, Dufour S, Richard R, Kaltenbach G, et al. Impact of short-term aerobic interval training on maximal exercise in sedentary aged subjects. Int J Clin Pr. 2009;63: 1472-1478. doi:10.1111/j.1742-1241.2009.02120.x

56. Adamson S, Kavaliauskas M, Yamagishi T, Phillips S, Lorimer R, Babraj J. Extremely short duration sprint interval training improves vascular health in older adults. Sport Sci Health. 2019;15: 123-131. doi:10.1007/s11332-018-0498-2

\section{Tables}

Table 1. Anthropometric characteristics and baseline variables of the participants

\begin{tabular}{|lcrl|}
\hline Variables & \multicolumn{1}{l}{$\mathrm{TG}_{\mathrm{A}}$} & \multicolumn{1}{l}{$\mathrm{TG}_{\mathrm{B}}$} & \multicolumn{1}{l|}{$\mathrm{CG}$} \\
& $\mathrm{M} \pm \mathrm{DP}$ & $\mathrm{M} \pm \mathrm{DP}$ & $\mathrm{M} \pm \mathrm{DP}$ \\
\hline Age (years) & $65.1 \pm 4.3$ & $73.1 \pm 7.2$ & $68.2 \pm 6.6$ \\
\hline Weight (kg) & $81.9 \pm 13.1$ & $74.2 \pm 7.3$ & $75.8 \pm 5.2$ \\
\hline Height (m) & $1.71 \pm 0.06$ & $1.69 \pm 0.06$ & $1.71 \pm 0.04$ \\
\hline BMI (kg/m $)$ & $27.8 \pm 1.4$ & $25.8 \pm 1.2$ & $26.8 \pm 1.4$ \\
\hline HR $(\mathrm{bpm})$ & $73 \pm 11$ & $76 \pm 14$ & $78 \pm 7$ \\
\hline SBP $(\mathrm{mm} / \mathrm{Hg})$ & $129 \pm 5$ & $128 \pm 10$ & $126 \pm 9$ \\
\hline DBP $(\mathrm{mm} / \mathrm{Hg})$ & $80 \pm 3$ & $77 \pm 6$ & $80 \pm 4$ \\
\hline
\end{tabular}

Table 2. P-values, effect size, and $\Delta \%$ for each condition. 


\begin{tabular}{|c|c|c|c|c|c|c|c|c|c|}
\hline & $\mathrm{TG}_{\mathrm{A}}$ & & & $\mathrm{TG}_{\mathrm{B}}$ & & & CG & & \\
\hline$H R_{R}$ & P-value & $\mathrm{EF}$ & $\Delta \%$ & P-value & $\mathrm{EF}$ & $\Delta \%$ & P-value & $E F$ & $\Delta \%$ \\
\hline $\begin{array}{l}\text { Post } \\
16^{\circ}\end{array}$ & $p=0.989$ & $\begin{array}{l}-0.06 \\
\text { (Trivial) }\end{array}$ & $-2 \%$ & $p=0.927$ & $\begin{array}{l}0.14 \\
\text { (Trivial) }\end{array}$ & $3 \%$ & $p=0.981$ & $\begin{array}{l}0.13 \\
\text { (Trivial) }\end{array}$ & $-2 \%$ \\
\hline $\begin{array}{l}\text { Post } \\
32^{\circ}\end{array}$ & $p=0.782$ & $\begin{array}{l}-0.31 \\
\text { (Small) }\end{array}$ & $-5 \%$ & $p=0.685$ & $\begin{array}{l}-0.31 \\
\text { (Small) }\end{array}$ & $-6 \%$ & $p=0.976$ & $\begin{array}{l}0.14 \\
\text { (Trivial) }\end{array}$ & $-2 \%$ \\
\hline \multicolumn{10}{|l|}{ SBP } \\
\hline $\begin{array}{l}\text { Post } \\
16^{\circ}\end{array}$ & $p=0.403$ & $\begin{array}{l}-0.86 \\
\text { (Large) }\end{array}$ & $4 \%$ & $p=0.173$ & $\begin{array}{l}0.67 \\
\text { (Medium) }\end{array}$ & $-5 \%$ & $p=0.458$ & $\begin{array}{l}0.51 \\
\text { (Medium) }\end{array}$ & $4 \%$ \\
\hline $\begin{array}{l}\text { Post } \\
32^{\circ}\end{array}$ & $p=0.219$ & $\begin{array}{l}-1.11 \\
\text { (Large) }\end{array}$ & $6 \%$ & $p=0.718$ & $\begin{array}{l}-0.29 \\
(\text { Small) }\end{array}$ & $-2 \%$ & $p=0.979$ & $\begin{array}{l}0.08 \\
\text { (Trivial) }\end{array}$ & $0.1 \%$ \\
\hline \multicolumn{10}{|l|}{ DBP } \\
\hline $\begin{array}{l}\text { Post } \\
16^{\circ}\end{array}$ & $p=0.998$ & $\begin{array}{l}0.12 \\
\text { (Trivial) }\end{array}$ & $0.1 \%$ & $p=0.987$ & $\begin{array}{l}-0.04 \\
\text { (Trivial) }\end{array}$ & $-0.1 \%$ & $p=0.987$ & $\begin{array}{l}0.23 \\
\text { (Small) }\end{array}$ & $1 \%$ \\
\hline $\begin{array}{l}\text { Post } \\
32^{\circ}\end{array}$ & $p=0.995$ & $\begin{array}{l}-0.20 \\
\text { (Small) }\end{array}$ & $-0.1 \%$ & $p=0.999$ & $\begin{array}{l}0.00 \\
\text { (Trivial) }\end{array}$ & $0.1 \%$ & $p=0.998$ & $\begin{array}{l}0.08 \\
\text { (Trivial) }\end{array}$ & $-0.1 \%$ \\
\hline \multicolumn{10}{|l|}{ MBP } \\
\hline $\begin{array}{l}\text { Post } \\
16^{\circ}\end{array}$ & $p=0.587$ & $\begin{array}{l}0.75 \\
\text { (Medium) }\end{array}$ & $-3 \%$ & $p=0.328$ & $\begin{array}{l}-0.71 \\
\text { (Medium) }\end{array}$ & $-4 \%$ & $p=0.328$ & $\begin{array}{l}0.51 \\
\text { (Medium) }\end{array}$ & $3 \%$ \\
\hline $\begin{array}{l}\text { Post } \\
32^{\circ}\end{array}$ & $p=0.328$ & $\begin{array}{l}-1.10 \\
\text { (Large) }\end{array}$ & $-4 \%$ & $p=0.819$ & $\begin{array}{l}-0.29 \\
(\text { Small) }\end{array}$ & $-2 \%$ & $p=0.960$ & $\begin{array}{l}0.09 \\
\text { (Trivial) }\end{array}$ & $0.1 \%$ \\
\hline \multicolumn{10}{|l|}{ DP } \\
\hline $\begin{array}{l}\text { Post } \\
16^{\circ}\end{array}$ & $p=0.913$ & $\begin{array}{l}-0.27 \\
\text { (Small) }\end{array}$ & $-5 \%$ & $p=0.961$ & $\begin{array}{l}-0.15 \\
\text { (Trivial) }\end{array}$ & $-3 \%$ & $p=0.905$ & $\begin{array}{l}0.12 \\
\text { (Trivial) }\end{array}$ & $2 \%$ \\
\hline $\begin{array}{l}\text { Post } \\
32^{\circ}\end{array}$ & $p=0.733$ & $\begin{array}{l}-0.52 \\
\text { (Medium) }\end{array}$ & $-10 \%$ & $p=0.733$ & $\begin{array}{l}-0.44 \\
\text { (Small) }\end{array}$ & $-9 \%$ & $p=0.942$ & $\begin{array}{l}-0.09 \\
\text { (Trivial) }\end{array}$ & $-1 \%$ \\
\hline \multicolumn{10}{|l|}{ RR } \\
\hline $\begin{array}{l}\text { Post } \\
16^{\circ}\end{array}$ & $p=0.990$ & $\begin{array}{l}0.14 \\
\text { (Trivial) }\end{array}$ & $2 \%$ & $p=0.725$ & $\begin{array}{l}0.26 \\
\text { (Small) }\end{array}$ & $5 \%$ & $p=0.610$ & $\begin{array}{l}0.46 \\
\text { (Small) }\end{array}$ & $3 \%$ \\
\hline $\begin{array}{l}\text { Post } \\
32^{\circ}\end{array}$ & $p=0.452$ & $\begin{array}{l}1.36 \\
\text { (Large) }\end{array}$ & $20 \%$ & $p=0.452$ & $\begin{array}{l}0.42 \\
\text { (Small) }\end{array}$ & $8 \%$ & $p=0.452$ & $\begin{array}{l}0.59 \\
\text { (Medium) }\end{array}$ & $4 \%$ \\
\hline \multicolumn{10}{|c|}{ RMSSD } \\
\hline $\begin{array}{l}\text { Post } \\
16^{\circ}\end{array}$ & $p=0.964$ & $\begin{array}{l}-0.20 \\
\text { (Small) }\end{array}$ & $-12 \%$ & $p=0.998$ & $\begin{array}{l}-0.01 \\
\text { (Trivial) }\end{array}$ & $-2 \%$ & $p=0.959$ & $\begin{array}{l}0.17 \\
\text { (Trivial) }\end{array}$ & $10 \%$ \\
\hline Post & $\mathrm{p}=0.987$ & 0.12 & $11 \%$ & $p=0.913$ & 0.12 & $14 \%$ & $p=0.985$ & 0.10 & $6 \%$ \\
\hline
\end{tabular}




\section{SDNN}

\begin{tabular}{|c|c|c|c|c|c|c|c|c|c|}
\hline $\begin{array}{l}\text { Post } \\
16^{\circ}\end{array}$ & $p=0.997$ & $\begin{array}{l}-0.06 \\
\text { (Trivial) }\end{array}$ & $-2 \%$ & $p=0.940$ & $\begin{array}{l}0.34 \\
\text { (Small) }\end{array}$ & $25 \%$ & $p=0.761$ & $\begin{array}{l}0.33 \\
\text { (Small) }\end{array}$ & $13 \%$ \\
\hline $\begin{array}{l}\text { Post } \\
32^{\circ}\end{array}$ & $p=0.752$ & $\begin{array}{l}-0.72 \\
\text { (Medium) }\end{array}$ & $-24 \%$ & $p=0.752$ & $\begin{array}{l}0.75 \\
\text { (Medium) }\end{array}$ & $54 \%$ & $p=0.752$ & $\begin{array}{l}0.34 \\
\text { (Small) }\end{array}$ & $14 \%$ \\
\hline \multicolumn{10}{|l|}{ LF } \\
\hline $\begin{array}{l}\text { Post } \\
16^{\circ}\end{array}$ & $p=0.930$ & $\begin{array}{l}-0.13 \\
\text { (Trivial) }\end{array}$ & $-5 \%$ & $p=0.920$ & $\begin{array}{l}-1.16 \\
\text { (Large) }\end{array}$ & $-9 \%$ & $p=0.381$ & $\begin{array}{l}0.54 \\
\text { (Medium) }\end{array}$ & $14 \%$ \\
\hline $\begin{array}{l}\text { Post } \\
32^{\circ}\end{array}$ & $p=0.381$ & $\begin{array}{l}-0.49 \\
\text { (Medium) }\end{array}$ & $-19 \%$ & $p=0.381$ & $\begin{array}{l}-4.00 \\
\text { (Large) }\end{array}$ & $-32 \%$ & $p=0.738$ & $\begin{array}{l}0.30 \\
\text { (Small) }\end{array}$ & $7 \%$ \\
\hline \multicolumn{10}{|l|}{ HF } \\
\hline $\begin{array}{l}\text { Post } \\
16^{\circ}\end{array}$ & $p=0.959$ & $\begin{array}{l}0.13 \\
\text { (Trivial) }\end{array}$ & $14 \%$ & $p=0.780$ & $\begin{array}{l}0.98 \\
\text { (Large) }\end{array}$ & $40 \%$ & $p=0.549$ & $\begin{array}{l}-0.34 \\
\text { (Small) }\end{array}$ & $-27 \%$ \\
\hline $\begin{array}{l}\text { Post } \\
32^{\circ}\end{array}$ & $p=0.549$ & $\begin{array}{l}0.50 \\
\text { (Medium) }\end{array}$ & $52 \%$ & $p=0.549$ & $\begin{array}{l}1.53 \\
\text { (Large) }\end{array}$ & $62 \%$ & $p=0.694$ & $\begin{array}{l}-0.27 \\
\text { (Small) }\end{array}$ & $-21 \%$ \\
\hline
\end{tabular}

\section{Table 2.}

Continuation

\section{$\mathrm{LF} / \mathrm{HF}$}

\begin{tabular}{|c|c|c|c|c|c|c|c|c|c|}
\hline $\begin{array}{l}\text { Post } \\
16^{\circ}\end{array}$ & $p=0.897$ & $\begin{array}{l}-0.32 \\
\text { (Small) }\end{array}$ & $-24 \%$ & $p=0.647$ & $\begin{array}{l}-0.58 \\
\text { (Medium) }\end{array}$ & $-20 \%$ & $p=0.435$ & $\begin{array}{l}1.16 \\
\text { (Large) }\end{array}$ & $91 \%$ \\
\hline $\begin{array}{l}\text { Post } \\
32^{\circ}\end{array}$ & $p=0.435$ & $\begin{array}{l}-0.90 \\
\text { (Large) }\end{array}$ & $-68 \%$ & $p=0.435$ & $\begin{array}{l}-0.80 \\
\text { (Large) }\end{array}$ & $-28 \%$ & $p=0.961$ & $\begin{array}{l}0.25 \\
\text { (Small) }\end{array}$ & $20 \%$ \\
\hline \multicolumn{10}{|c|}{$\mathrm{VO}_{2 \max }$} \\
\hline $\begin{array}{l}\text { Post } \\
16^{\circ}\end{array}$ & $p=0.996$ & $\begin{array}{l}0.82 \\
\text { (Large) }\end{array}$ & $11 \%$ & $p=0.995$ & $\begin{array}{l}0.31 \\
\text { (Small) }\end{array}$ & $5 \%$ & $p=0.999$ & $\begin{array}{l}0.00 \\
\text { (Trivial) }\end{array}$ & $0.001 \%$ \\
\hline $\begin{array}{l}\text { Post } \\
32^{\circ}\end{array}$ & $p=0.992$ & $\begin{array}{l}1.12 \\
\text { (Large) }\end{array}$ & $15 \%$ & $p=0.992$ & $\begin{array}{l}0.38 \\
\text { (Small) }\end{array}$ & $6 \%$ & $p=0.992$ & $\begin{array}{l}0.03 \\
\text { (Trivial) }\end{array}$ & $0.07 \%$ \\
\hline
\end{tabular}

$\mathrm{TG}_{\mathrm{A}}=$ Training Group $\mathrm{A} ; \mathrm{TG}_{\mathrm{B}}=$ Training Group $\mathrm{B} ; \mathrm{CG}=$ Control Group; Post $\mathbf{1 6}^{\circ}=$ Sixteen weeks post intervention; Post $\mathbf{3 2}^{\circ}=$ Thirty-two weeks post intervention; $\mathrm{HR}_{\mathrm{R}}=$ Resting Heart Rate; $\mathrm{SBP}=$ Systolic Blood Pressure; $\mathrm{DBP}=$ Diastolic Blood Pressure; MBP= Mean Blood Pressure; $D P=$ Double Product; RR= R-R index; RMSSD= RMSSD index; $S D N N=S D N N$ index; $L F=L_{N U}$ index; $H F=H F_{N U}$ index; LF/HF= LF/HF ratio; $V_{2 \max }=$ Maximum Oxygen Uptake

\section{Figures}




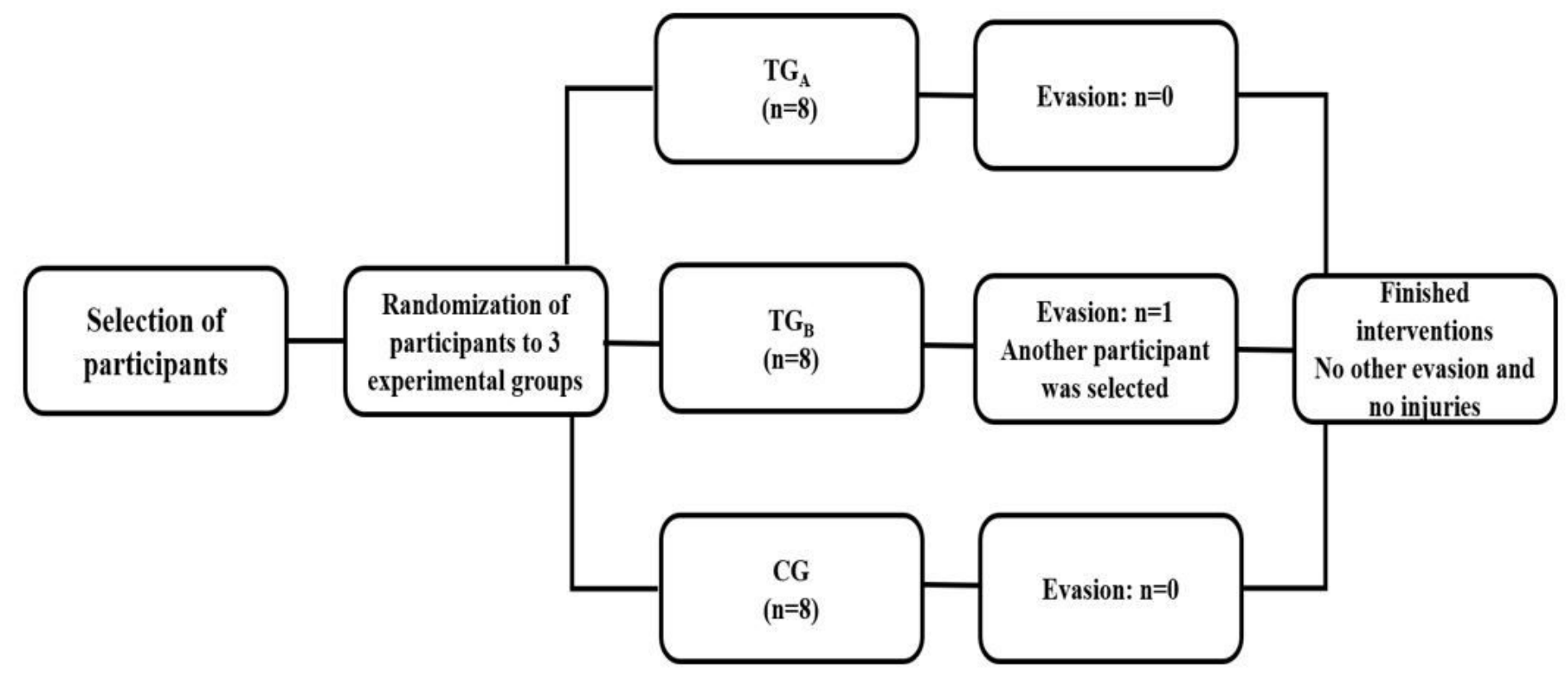

Figure 1

Flowchart of the entire intervention process for all groups

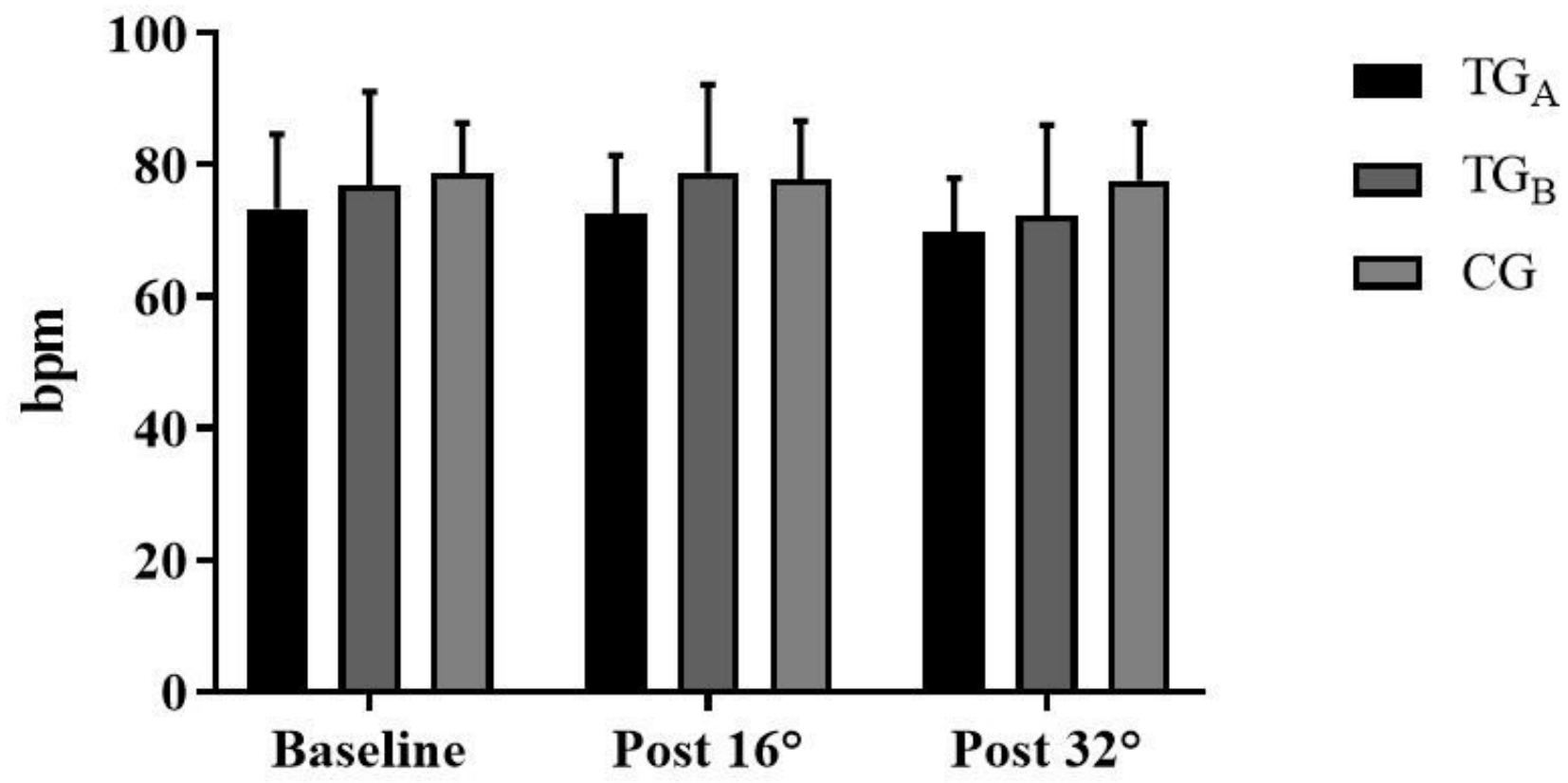

Figure 2

Heart rate values. Post $16^{\circ}=$ Sixteen weeks post-intervention; Post $32^{\circ}=$ Thirty-two weeks post-intervention. TGA $=$ Training Group A; TGB = Training Group B; CG = Control Group 

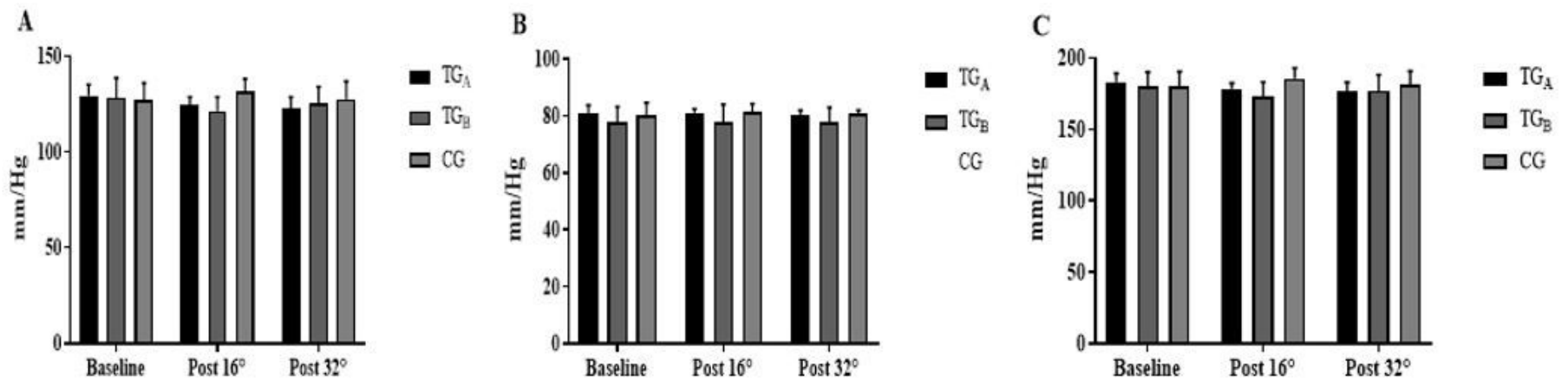

Figure 3

Blood pressure values between each moment. $(A)=$ Systolic Blood Pressure; $(B)$ = Diastolic Blood Pressure; $(C)$ Means Blood Pressure; Post $16^{\circ}=$ Sixteen weeks post-intervention; Post $32^{\circ}=$ Thirty-two weeks post-intervention. TGA = Training Group A; TGB = Training Group B; CG = Control Group.

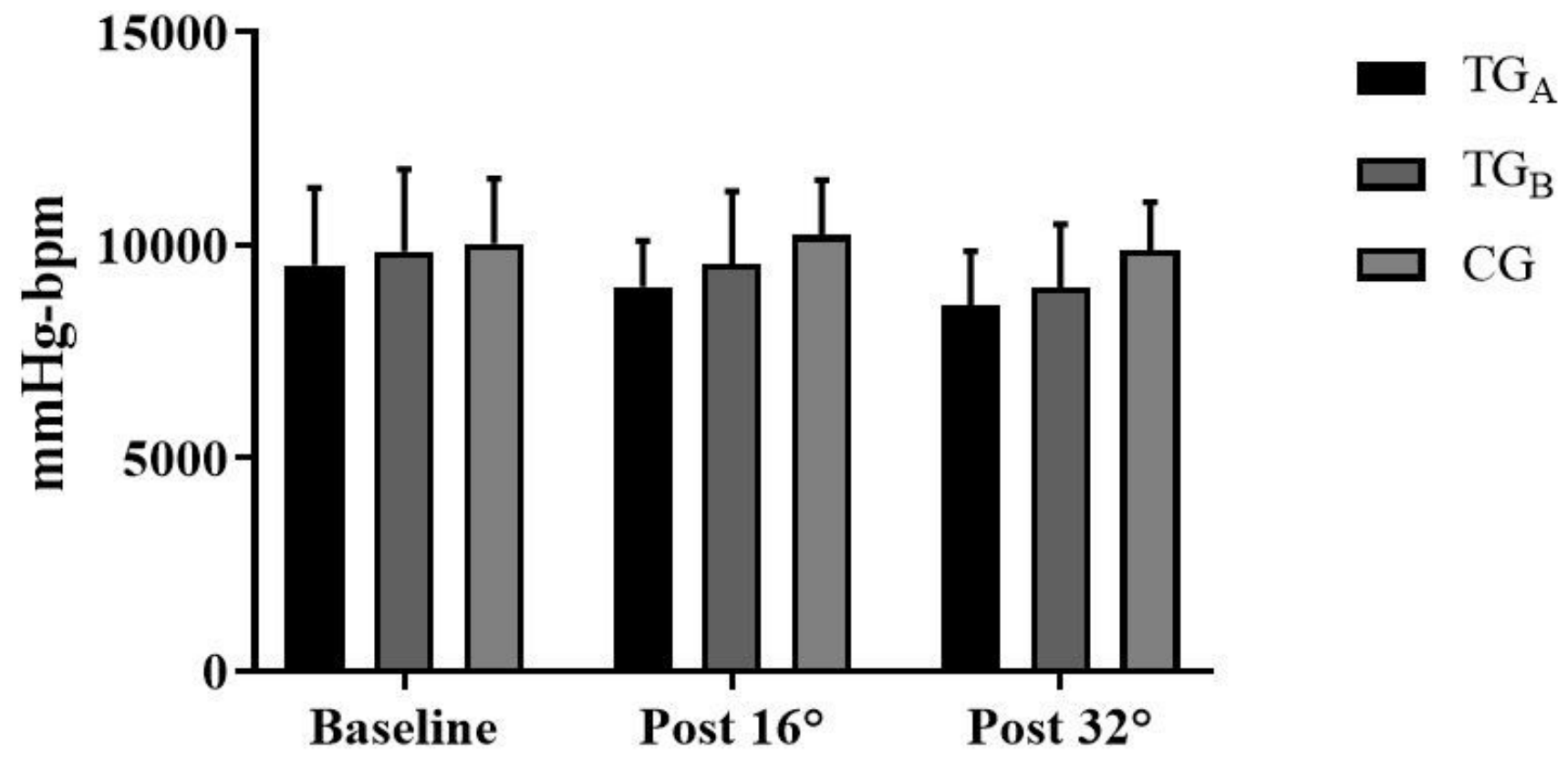

Figure 4

Double Product. Post $16^{\circ}=$ Sixteen weeks post-intervention; Post $32^{\circ}=$ Thirty-two weeks post-intervention. TGA = Training Group A; TGB = Training Group B; CG = Control Group. 

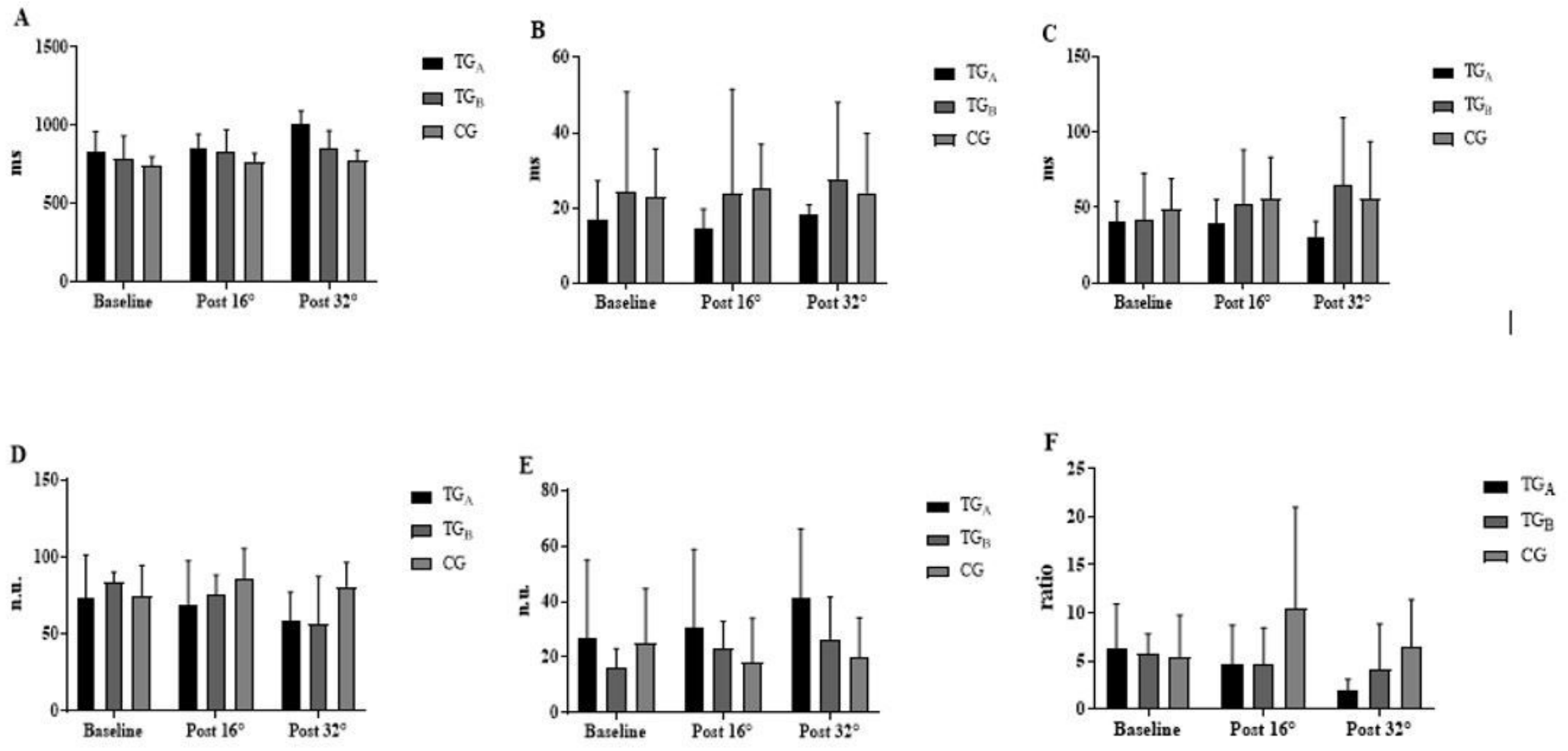

Figure 5

Heart rate variability. $(A)=R-R$ index; $(B)=$ RMSSD index; (C) SDNN index); (D) LFNU index; (E) = HFNU index; (F) $\mathrm{LF} / \mathrm{HF}$ ratio. Post $16^{\circ}=$ Sixteen weeks post intervention; Post $32^{\circ}=$ Thirty-two weeks post intervention. $T G A=$ Training Group A; TGB = Training Group B; CG = Control Group.

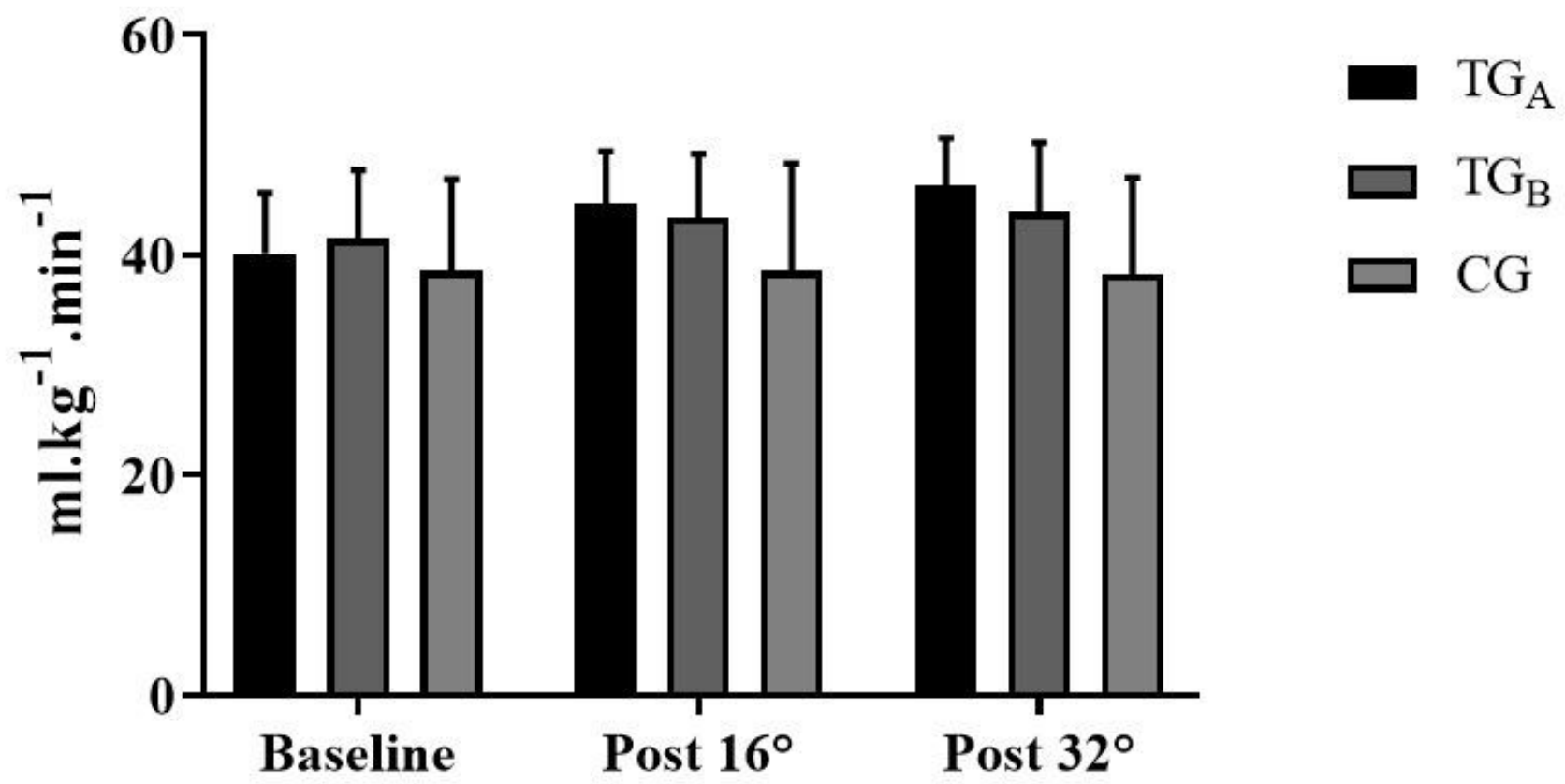

Figure 6 
V02max estimate $(\mathrm{ml} / \mathrm{min})$. Post $16^{\circ}=$ Sixteen weeks post-intervention; Post $32^{\circ}=$ Thirty-two weeks postintervention. TGA = Training Group A; TGB = Training Group B; CG = Control Group. 